\title{
Molecular characterization of the restriction endonuclease gene (scrFIR) associated with the ScrFI restriction/modification system from Lactococcus lactis subsp. cremoris UC503
}

\author{
Denis P. Twomey, ${ }^{1}+$ Nathalie Gabillet, ${ }^{1,2}$ Charles Daly ${ }^{1,2}$ \\ and Gerald F. Fitzgerald ${ }^{1,2}$ \\ Author for correspondence: Gerald F. Fitzgerald. Tel: +353 21 902730. Fax: +35321275934. \\ e-mail: g.fitzgerald@ucc.ie
}

Department of Microbiology ${ }^{1}$ and National Food Biotechnology Centre 2 University College, Cork, Ireland
The nucleotide sequence of the chromosomally encoded type II ScrfI restriction/modification system from Lactococcus lactis subsp. cremoris UC503 was completed. The ScrFI restriction endonuclease (ENase) has previously been shown to specifically recognize $5^{\prime}$ CCNGG $3^{\prime}$ sites, cleaving after the second cytosine and the degenerate central base. The ENase gene (scrFIR; 862 bp) was located between, and co-directionally transcribed with, two formerly characterized 5-methylcytosine methyltransferase genes, which encode proteins that independently confer protection against ScrfI digestion. SCrFIR codes for a protein of $\mathbf{2 7 2}$ amino acids with a predicted molecular mass of $31470 \mathrm{Da}$, which agrees favourably with a previously estimated molecular mass of $34 \mathrm{kDa}$ for this enzyme. The deduced sequence of this protein did not show any significant homology with known protein sequences, including the isoschizomeric Ssoll ENase from Shigella sonnei. The ENase gene was cloned and expressed in Escherichia coli and Lactococcus; however, no in vivo restriction of phage was observed, suggesting that expression of the ENase gene may be repressed, or that the appropriate expression signals may be absent in the cloned constructs. The ability of Scrfl to cleave non-canonically modified 5' CCNGG 3 ' sequences suggested that some Scrfl sites may require complex modifications to fully impair digestion by this enzyme.

Keywords: bacteriophage resistance, lactic acid bacteria, endonuclease, methyltransferase

\section{INTRODUCTION}

The mesophilic lactococci are important functional components in a variety of dairy fermentations, where they contribute to a number of necessary and desirable characteristics including product $\mathrm{pH}$, flavour, texture and aroma. One of the factors governing the choice of the strains employed is their insensitivity to phage infection. Efforts to limit the potentially drastic consequences of phage infection have stimulated intensive

†Present address: Department of Food Science and Nutrition, University of Minnesota, St Paul, MN 55108, USA.

Abbreviations: ENase, restriction endonuclease; $5 \mathrm{mC}$, 5-methylcytosine; MTase, methyltransferase; R/M, restriction/modification.

The GenBank/EMBL accession number for the nucleotide sequence reported in this paper is U89998. research aimed at understanding phage-host interactions. Genetic approaches are being increasingly used to dissect these relationships at a molecular level, with one of the primary goals being the development of super-immune strains which remain insensitive to a range of phages over prolonged production regimes. These studies have led to the identification of at least four types of natural phage resistance mechanisms in lactococci, including adsorption blocking, injection blocking, abortive infection, and restriction and modification $(\mathrm{R} / \mathrm{M}$ ) systems (for a recent review see Garvey et al., 1995).

$\mathrm{R} / \mathrm{M}$ systems are the most frequently encountered resistance mechanism in Lactococcus, where they are typically plasmid-encoded (Hill, 1993; Klaenhammer \& Fitzgerald, 1994; Garvey et al., 1995). The nucleotide sequences of three complete systems have been pub- 
lished: LlaI (Hill et al., 1991; O'Sullivan et al., 1995), Lla DCHI (previously referred to as LlaII ; Moineau et al., 1995) and LlaBI (Nyengaard et al., 1996). In addition, the sequences of two chromosomally encoded methyltransferases (MTases) associated with the ScrFI R/M system from L. lactis subsp. cremoris UC503 (previously designated Streptococcus cremoris F; Schleifer \& Kilpper-Bälz, 1987) have also been reported (Davis et al., 1993; Twomey et al., 1993). As in other R/M systems, the deduced amino acid sequences of all the lactococcal MTases contain distinguishing motifs which simplify their identification from primary sequence data (Klimasauskas et al., 1989; Pósfai et al., 1989; Wilson, 1992; Noyer-Weidner \& Trautner, 1993; Kumar et al., 1994; Timiniskas et al., 1995). In contrast, no universally conserved motif persists throughout the restriction endonuclease (ENase) sequences, which are more heterogeneous and generally only show significant primary sequence homology with related isoschizomers. This is illustrated by the LlaDCHI ENase, which recognizes $5^{\prime}$ GATC 3' sites and shows significant identity with its isoschizomers DpnII (31\%) and MboI (34\% ; Moineau et al., 1995) but has relatively little homology with other ENases. While the majority of type II ENases do not have any obvious homology at the primary sequence level, X-ray crystallography studies suggest that many of these proteins may have similar tertiary structures, especially throughout the active-site residues, with more extensive structural homology among ENases that generate similar cleavage patterns (Anderson, 1993; Aggarwal, 1995).

Here the completed sequence of the $S c r F I R / M$ locus is presented. The restriction gene (scrFIR) has been identified as being located between the two previously characterized MTase genes (Davis et al., 1993; Twomey et al., 1993). Unlike the cognate MTases, which show significant similarities with other 5-methylcytosine MTases, the deduced amino acid sequence of the $S_{c r F I}$ ENase is very different from other type II ENases, including isoschizomeric enzymes. The ability of $S c r F I$ to cleave at its recognition site when some of the residues are methylated at the 5 -carbon position is investigated.

\section{METHODS}

Bacterial strains, phage, plasmids and media. The bacterial strains, bacteriophage and plasmids used in this study are listed in Table 1 . Escherichia coli strains were grown at $37^{\circ} \mathrm{C}$ in LB agar (Sambrook et al., 1989). Where necessary, the antibiotics ampicillin (Ap; $100 \mu \mathrm{g} \mathrm{ml}^{-1}$ ), chloramphenicol $\left(\mathrm{Cm} ; 25 \mu \mathrm{g} \mathrm{m}^{-1}\right.$ ) or tetracycline (Tet; $10 \mu \mathrm{g} \mathrm{ml}^{-1}$ ) were added to media. Lactococcal strains and their phage were routinely grown without shaking at $30^{\circ} \mathrm{C}$ in M17 medium (Terzaghi \& Sandine, 1975) containing either glucose or lactose as required $(0.5 \%)$. Lactococcal cells containing $\mathrm{pCI} 372$ and various derivatives were selected and maintained by the addition of $\mathrm{Cm}\left(5 \mu \mathrm{g} \mathrm{ml}^{-1}\right)$.

Enzymes, molecular cloning and sequencing procedures. Restriction enzymes, modification MTases, T4 DNA ligase and Klenow fragment from DNA polymerase I were purchased from either New England Biolabs, Boehringer or Stratagene and used according to the manufacturers' instructions. Plas- mid DNA was isolated from $E$. coli using the cleared lysate technique (Sambrook et al., 1989) or by the method of Anderson \& McKay (1983) for lactococcal DNA. Electrotransformation of DNA was accomplished using a Bio-Rad Gene Pulser apparatus and was performed according to manufacturer's instructions for E. coli cells or by the method described by Holo \& Nes (1989) for Lactococcus. The nucleotide sequence of both strands of alkali-denatured doublestranded DNA was determined by the dideoxy chain-termination method (Sanger et al., 1977) using a Sequenase II sequencing kit (United States Biochemical). Primers for sequencing were synthesized using an Applied Biosystems PCR-MATE DNA synthesizer.

Plasmid constructs and deletion derivatives. Reconstruction of the parental organization of the $S c r F I R / M$ locus was accomplished by cloning an EcoRI/Sau3A fragment from pCI931m into the multiple cloning site of pBluescript KS I, followed by the introduction of an EcoRI-NruI fragment from pCI932m, generating a construct designated pCI933. The E. coli-L. lactis shuttle vector pCI372 was employed for the reintroduction of the $S c r F I R / M$ chromosomal region into L. lactis. An XhoI-Sau3A fragment from pCI933 was introduced into the compatible SalI/BamHI sites within the multiple cloning site of $\mathrm{pCI} 372$, resulting in the formation of pCI934. A specific in-frame deletion of 582 bp from $s c r F I R$ was constructed by digesting pCI933 with EcoRI and NdeI, followed by filling in the recessed $3^{\prime}$ ends with Klenow fragment from DNA polymerase I and religating. A construct designated pCI940, containing scrFIBM, scrFIR and scrFIAM, with a disrupted orf $X$, was constructed by cloning an HaeIII-Sau3A fragment into the multiple cloning site of pCI372.

Assay for ENase activity. In vitro biochemical assays and plaque assays were used to assess constructs for ENase activity. Overnight cultures of E. coli and L. lactis were pelleted by centrifugation, washed in quarter-strength Ringer's solution and resuspended in $0.75 \mathrm{ml}$ ice-cold extraction buffer : 0.05 M Tris/ $\mathrm{HCl} \mathrm{pH} \mathrm{7.5,} 1 \mathrm{mM} \mathrm{Na}{ }_{2}$ EDTA and $7 \mathrm{mM} \mathrm{2-}$ mercaptoethanol. Cells were ruptured by adding $0.5 \mathrm{~g}$ glass beads (106 $\mu \mathrm{m}$ and finer; Sigma) and vibrated for $7 \mathrm{~min}$ using a 'Shake it Baby' cell disrupter (Biospec Products). Cellular debris was removed by centrifugation (approx. $14000 \mathrm{~g}$, $10 \mathrm{~min}$ ) and a $10 \mu \mathrm{l}$ aliquot of the cell-free extract was analysed for its ability to digest $1 \mu \mathrm{g}$ pBR322 DNA in a $40 \mu \mathrm{l}$ reaction mixture corcaining $10 \mathrm{mM}$ Tris/ $\mathrm{HCl} \mathrm{pH} \mathrm{7.5,5} \mathrm{mM} \mathrm{MgCl}_{2}$, $100 \mathrm{mM} \mathrm{NaCl}, 5 \mathrm{mM}$ dithiothreitol and $2 \mathrm{mM} 2$-mercaptoethanol. Reactions were incubated at $37^{\circ} \mathrm{C}$ for $60 \mathrm{~min}$ followed by electrophoresis. Biological ScrFI activity was assessed by comparing the titres of the lactococcal phage $\phi \mathrm{c} 2$ on the host of interest relative to a non-restricting host. Enumeration of phage was performed by mixing $1 \mathrm{ml}$ of the appropriate phage dilution with $0.1 \mathrm{ml}$ of an overnight culture of L. lactis, adding the mixture to $3 \mathrm{ml}$ prewarmed $\left(45^{\circ} \mathrm{C}\right)$ soft agar $(0.75 \%)$ supplemented with $2 \mathrm{mM} \mathrm{CaCl}_{2}$ and pouring onto prepoured agar. The efficiency of plaquing (EOP) of bacteriophage was defined as (phage titre on the host of interest)/(phage titre on a non-restricting host).

Assay for activity of ScrFI on 5-methylcytosine-modified DNA. The effect of non-canonical 5 -methylcytosine $(5 \mathrm{mC})$ modifications on impairing DNA cleavage by the $S c r F I$ ENase was assayed using in vitro-methylated DNA. pBR322 DNA was isolated from a $\mathrm{dcm}^{+} E$. coli strain (RR1) and $1 \mu \mathrm{g}$ was methylated in vitro with $6 \mathrm{U}$ of M.SssI or M.MspI in the presence of $80 \mu \mathrm{M} S$-adenosyl-L-methionine for at least $4 \mathrm{~h}$ in the appropriate buffer as recommended by the manufacturer (New England Biolabs). One MTase unit was defined as the 
Table 1. Bacteria, bacteriophage and plasmids

\begin{tabular}{|c|c|c|}
\hline & Relevant genotype or phenotype & Reference or source \\
\hline \multicolumn{3}{|l|}{ Bacteria } \\
\hline E. coli & $\Delta(m c r A) 183 \Delta(m c r B C-h s d S M R-m r r) 173$ endA1 supE44 thi-1 recA1 & Stratagene \\
\hline \multicolumn{3}{|c|}{ XL1-Blue MRF gyrA96 relA1 $\left[\mathrm{F}^{\prime}\right.$ proAB lacl $\left.{ }^{\mathrm{a}} \mathrm{Z} \Delta \mathrm{M} 15 \mathrm{Tn} 10\left(\mathrm{Tet}^{\mathrm{r}}\right)\right]$} \\
\hline RR1 & $\begin{array}{l}\mathrm{F}^{-} \Delta(g p t-p r o A) 62 \text { leu supE44 ara-14 galK2 lacY1 } \Delta(m c r C-m r r) \\
\quad r p s L 20\left(\mathrm{Str}^{\mathrm{r}}\right) x y l-5 \mathrm{mtl}-1 \mathrm{rec} A^{+}\end{array}$ & Sambrook et al. (1989) \\
\hline \multicolumn{3}{|l|}{$\begin{array}{l}\text { L. lactis subsp. } \\
\text { cremoris }\end{array}$} \\
\hline MG1363 & Plamid-free derivative of L. lactis subsp. cremoris 712 & Gasson (1983) \\
\hline UC503 & $\begin{array}{l}\text { Isolate from Irish Cheddar cheese mixed-strain starter encoding } S c r F I \\
\mathrm{R} / \mathrm{M} \text { activity }\end{array}$ & $\begin{array}{l}\text { Fitzgerald et al. (1982) } \\
\text { Costello (1988) }\end{array}$ \\
\hline UC563 & $\begin{array}{l}\text { Derivative of } L \text {. lactis subsp. cremoris UC503 cured of the phage- } \\
\text { resistance adsorption-blocking plasmid pCI528 }\end{array}$ & \\
\hline \multicolumn{3}{|l|}{ Bacteriophage } \\
\hline$\phi \mathrm{c} 2$ & Prolate-headed lactococcal phage susceptible to $S c r F I$ restriction & UCC Phage Collection \\
\hline \multicolumn{3}{|l|}{ Plasmids } \\
\hline $\mathrm{pCI} 372$ & $5.7 \mathrm{~kb}$ E. coli-L. lactis shuttle vector, $\mathrm{Cm}^{\mathrm{r}}$ & Hayes et al. (1990) \\
\hline pCI931m & $\begin{array}{l}\text { pBR322-based chimeric construct containing scrFIAM modification gene } \\
\text { from L. lactis subsp. cremoris UC503, } \mathrm{Ap}^{\mathrm{r}}\end{array}$ & Davis et al. (1993) \\
\hline $\mathrm{pCI} 932 \mathrm{~m}$ & $\begin{array}{l}\text { pBR322-based chimeric construct containing scrFIBM modification gene } \\
\text { from } L \text {. lactis subsp. cremoris UC503, } \mathrm{Ap}^{\mathrm{r}}\end{array}$ & Davis et al. (1993); Twomey (1996) \\
\hline pCI933 & $\begin{array}{l}\text { pBluescript-based construct with a } 4.2 \mathrm{~kb} \text { NruI-Sau3A fragment from } L \text {. } \\
\text { lactis subsp. cremoris UC503 containing orfX, scrFIBM, scrFIR and } \\
\text { scrFIAM, Ap }{ }^{\mathrm{r}}\end{array}$ & This study \\
\hline pCI934 & $\begin{array}{l}\text { pCI372-based construct with } 4.2 \mathrm{~kb} \text { Xhol-Sau3A fragment from pCI933 } \\
\text { containing orfX scrFIBM, scrFIR and scrFIAM, } \mathrm{Cm}^{\mathrm{r}}\end{array}$ & This study \\
\hline pCI940 & $\begin{array}{l}\text { pCI1372-based construct with a } 3.8 \mathrm{~kb} \text { HaeIII-Sau3A fragment from } \\
\text { pCI933 containing scrFIBM, scrFIR and } s c r F I A M, \mathrm{Cm}^{\mathrm{r}}\end{array}$ & This study \\
\hline pCI942 & Derivative of pCI933 with an EcoRI-NdeI deletion internal to $s c r F I R, \mathrm{Ap}^{\mathrm{r}}$ & This study \\
\hline pBluescript KS I & E. coli cloning vector, $\mathrm{Ap}^{\mathrm{r}}$ & Stratagene \\
\hline pBR322 & E. coli cloning vector, $\mathrm{Ap}^{\mathrm{r}} \mathrm{Tet}^{\mathrm{r}}$ & Bolivar et al. (1977) \\
\hline
\end{tabular}

amount of enzyme required to fully protect $1 \mu \mathrm{g} \lambda \mathrm{DNA}$ in $1 \mathrm{~h}$ at $37^{\circ} \mathrm{C}$ in a $10 \mu \mathrm{l}$ reaction mixture against digestion by an appropriate ENase. To demonstrate complete modification, the in vitro-methylated plasmid DNA was treated with $5 \mathrm{U}$ of either HpaII or MspI for $1 \mathrm{~h}$, where appropriate, and examined for products of ENase activity using agarose gel electrophoresis. Incubation of fully modified DNA with ScrFI was used to assess the effect of non-canonical $5 \mathrm{mC}$ modifications on cleavage by this ENase. One ENase unit was defined as the amount of enzyme able to digest $1 \mu \mathrm{g}$ of $\lambda$ DNA at $37^{\circ} \mathrm{C}$ in $1 \mathrm{~h}$.

Sequence data analysis. This was performed using the DNASTAR software and the facilities available at the Irish National Centre for BioInformatics (INCBI, Trinity College, Dublin, Ireland).

\section{RESULTS}

\section{Sequencing and phenotypic analysis of the ScrfI R/M system}

L. lactis subsp. cremoris UC503 was isolated from a mixed-strain starter culture employed in the Irish Cheddar cheese industry and was previously shown to encode a type II restriction ENase, ScrFI, which recognizes the sequence $5^{\prime}$ CC ${ }^{\downarrow}$ NGG $3^{\prime}$ and cleaves as indicated (Fitzgerald et al., 1982). Two constructs, pCI931m and pCI932m, were isolated from the chromosome of this strain; each encoded a $5 \mathrm{mC}$ MTase which conferred resistance to $S c r$ FI digestion (Davis et al., 1993; Twomey et al., 1993). Inverse PCR analyses coupled to Southern hybridization suggested that the two EcoRI-Sau3A fragments from these MTase-encoding constructs were adjacent to each other on the lactococcal chromosome, sharing a common EcoRI site. To confirm this organization and to exclude the possibility of two closely associated EcoRI sites occurring at this location, this region of the chromosome was amplified by PCR and sequenced directly. In agreement with the earlier work of Davis et al. (1993), this analysis indicated that the inserts of pCI931 $\mathrm{m}$ and pCI932 $\mathrm{m}$ are indeed contiguous on the UC503 chromosome, sharing an EcoRI site (Twomey, 1996).

The sequences of two $5 \mathrm{mC}$ MTase genes from pCI931m and pCI932 $\mathrm{m}$ have been previously reported (Davis et al., 1993; Twomey et al., 1993). The sequences of the 


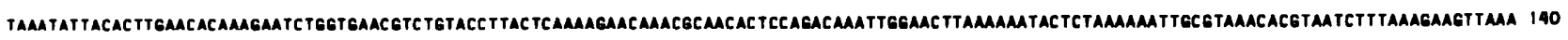

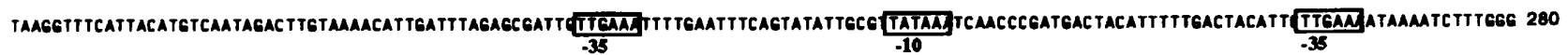

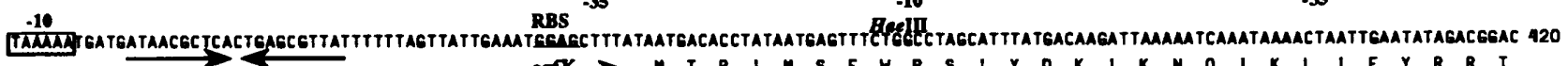
or $X \rightarrow$ M T P I H S F W P S I Y O K I K N O I K L I E Y R R T

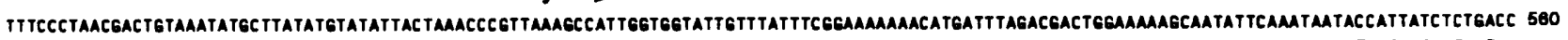

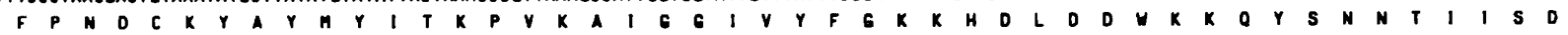

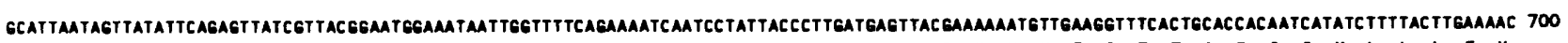
R I N S Y I O S Y R Y E N E I I G F O K I N P I T L D E L R K N V E E F T A P O $S Y$ S L L E N

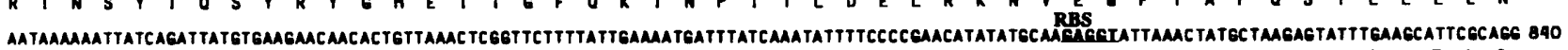

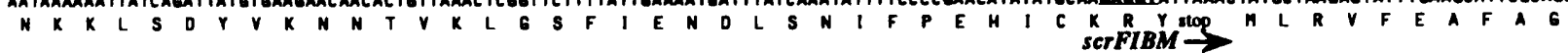

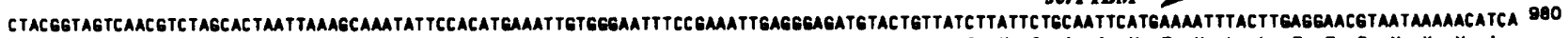
$Y G S O R L A L I K A N I P H E I V G I S E$; E G O V L L S Y S A I H E N L L E E R N K N I

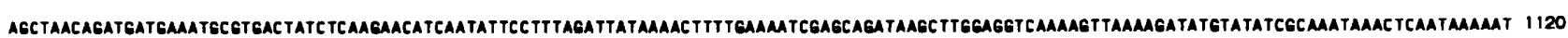

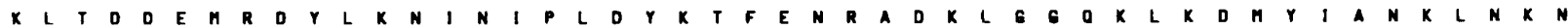

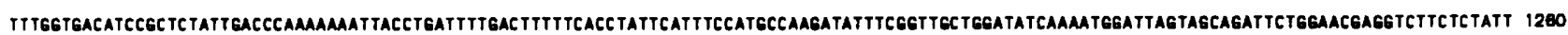

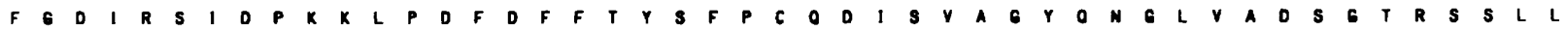

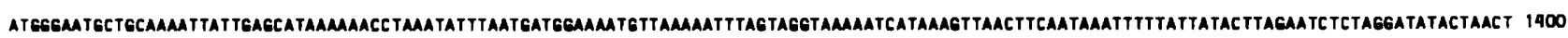

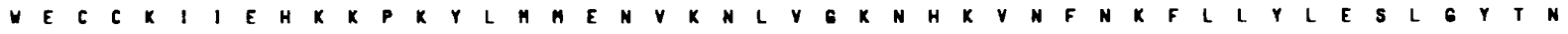

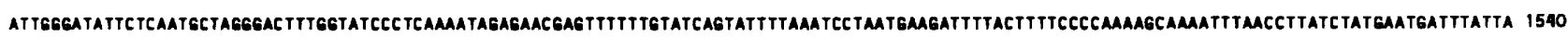
$Y$ D I L N A R D F I I P O N R E R V F C I S I L N P N E D F T F P O K O N L T L S N N D L L

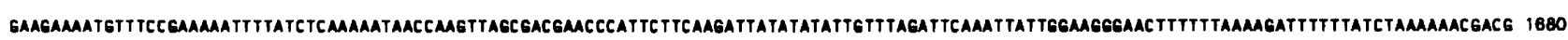
E E N S S E K F Y L K N N O V S O E P I L O D Y I Y C L D S N Y W K G T F L K D F L S K K R R

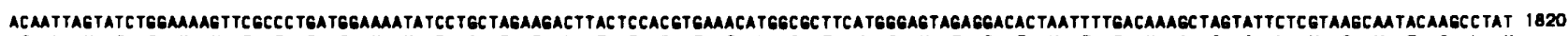

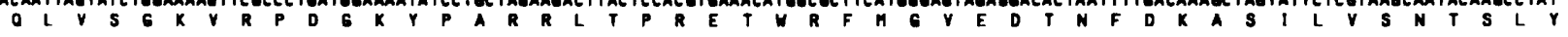

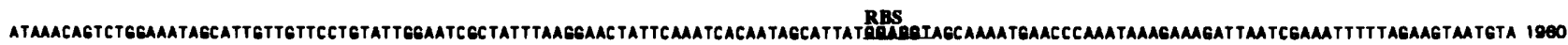

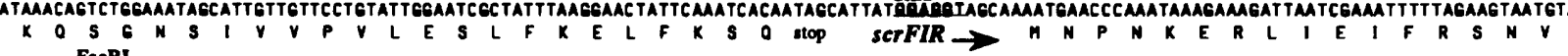
aAagca Ecapi

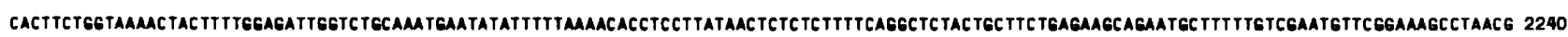
T S E K T T F G D W S A N E Y I F K T P P Y N S L F S G S T A S E K O N A F C R A F G K P N

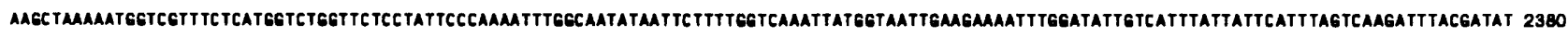

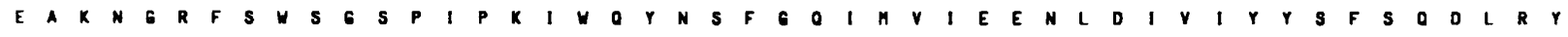

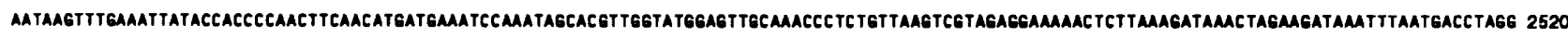

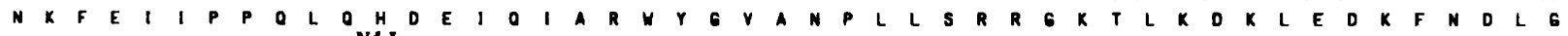

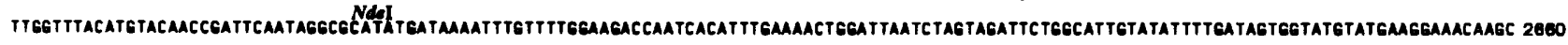
* F T G T T O S I G A Y D K I G F G R P I T F E N W I N L V D S G I V Y F D S G A Y E G N K

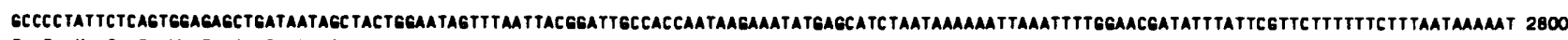
R P Y S O K R A O N S Y N N S L T T D C H Q slop

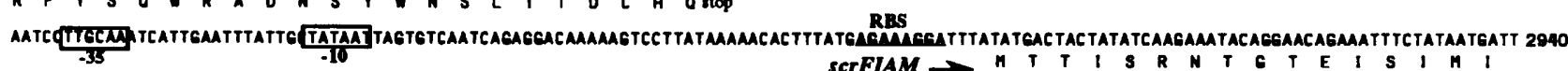

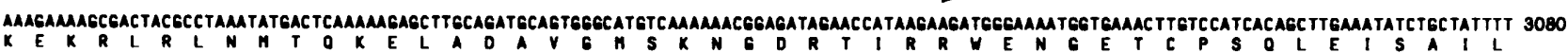

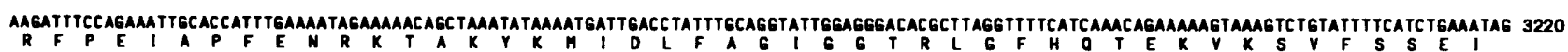
ataantitgctattaanact

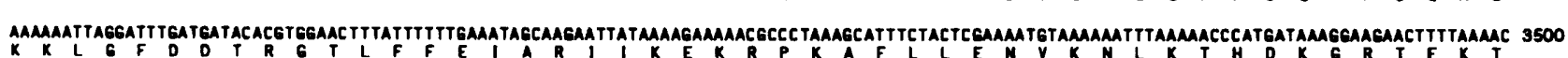

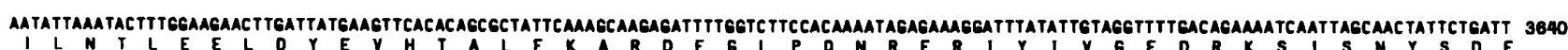

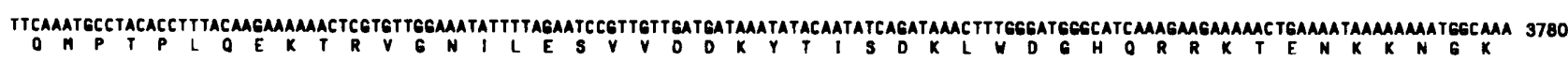

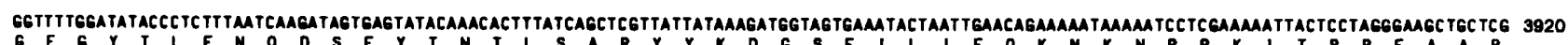

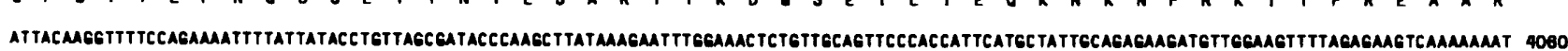
$L$ O G F P E N F 1 I P V S O T O A Y K E F G N S V A V P T I H A I A E K N L E V LE K S K K Stop

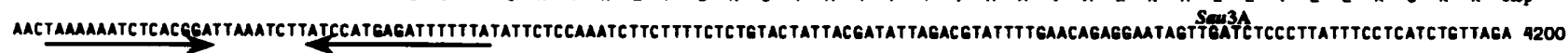

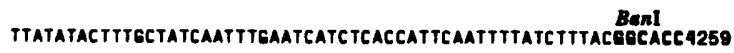

Fig. 1. Completed nucleotide sequence of the SCrFI R/M system and deduced amino acid sequences encoded by orf $X$, scrFIBM, scrFIR and scrFIAM. The sequences of two $5 \mathrm{mC}$ MTase genes, scrFIBM (Twomey et al., 1993; GenBank accession no. L12227) and scrFIAM (Davis et al., 1993; GenBank accession no. M87289) have been reported previously. The direction of transcription is illustrated by short arrows following the gene designations. Sequences equivalent to $E$. coli -10 and -35 promoter sequences are boxed. Predicted ribosome-binding sites are denoted RBS and underlined. Facing arrows indicate sequences likely to form significant secondary structures. Restriction sites used in cloning and in the formation of a number of plasmid constructs are also indicated. 


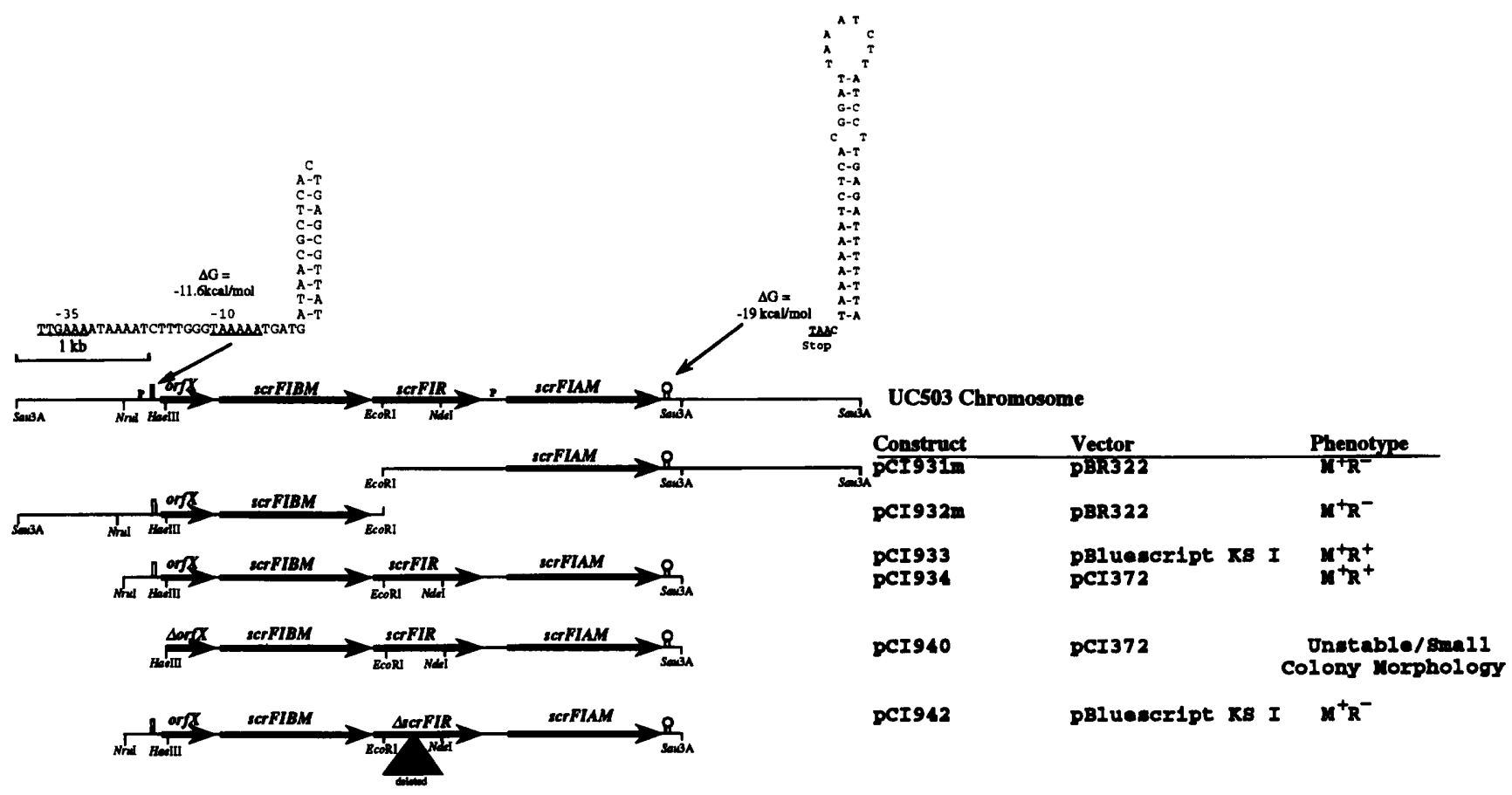

Fig. 2. Schematic representation of the lactococcal inserts contained in plasmid constructs used in this study. The arrows represent ORFs and a stippled triangle illustrates a deleted fragment. Regions containing sequences consistent with lactococcal promoter sequences are marked P. Sequences likely to form significant secondary structures are depicted by a graphical representation of the predicted structure. Appropriate restriction sites used in cloning and mutational analyses are also indicated. The $R^{+} / R^{-}$phenotype designations refer to ENase assays of cell-free extracts.

remainder of the chromosomal inserts of these plasmids, spanning a region of $6045 \mathrm{bp}$ in total, were determined. PCR analysis indicated that fragments flanking a Sau3A site in this region (Fig. 1, nucleotide 4172) were contiguous on the UC503 genome, indicating that this site, which lies immediately downstream of scrFIAM, was not cleaved by the partial Sau3A digest used in the original cloning of the $S c r F I$ MTases. In addition to the previously described ORFs (scrFIAM, scrFIBM and orfX; Davis et al., 1993; Twomey et al., 1993), analysis of other putative ORFs in this region identified one initiating 19 nucleotides downstream of the translational stop codon of scrFIBM and spanning the EcoRI site common to both inserts (Figs 1 and 2). This ORF is preceded by an appropriately spaced ribosome-binding site which bears complementarity to the $3^{\prime}$ end of $L$. lactis 16s rRNA and has a predicted free energy of $-16 \cdot 2$ $\mathrm{kcal} \mathrm{mol}^{-1}\left(-67.8 \mathrm{~kJ} \mathrm{~mol}^{-1}\right)$ at $25^{\circ} \mathrm{C}$. Furthermore, the deduced protein had a predicted molecular mass $(31470 \mathrm{Da})$ in good agreement with the previously estimated molecular mass $(34 \mathrm{kDa})$ of a partially purified preparation of $S c r F I$ (Davis, 1992).

As the genetic loci responsible for encoding ENase and MTase activities in type II systems are invariably relatively close to each other, with intervening distances between the respective genes rarely greater than $0.7 \mathrm{~kb}$ (Wilson \& Murray, 1991), the ORF between the two ScrFI MTase genes was investigated to determine if it encoded the $S c r$ FI ENase. A two-step cloning strategy was employed to reconstruct the parental organization of this putative ORF in which a $2 \cdot 2 \mathrm{~kb}$ EcoRI-Sau3A fragment from pCI931m was first cloned into pBluescript KS I, followed by the introduction of a $2.0 \mathrm{~kb}$ NruI-EcoRI fragment from pCI932m (Fig. 2). This construct, designated pCI933, was electrotransformed into $E$. coli XL1-Blue MRF' and cell-free extracts of the transformants were examined for in vitro ScrFI activity (Fig. 3, lane 6). Incubation with pBR322 ( $\left.\mathrm{Dcm}^{-}\right)$clearly indicated type II ENase activity, which was consistent with similar activity observed in the parent ScrFIproducing strain, L. lactis subsp. cremoris UC503, and which was absent in the plasmid-free E. coli XL1-Blue $M \mathrm{MF}^{\prime}$ (Fig. 3, lanes 3 and 5, respectively). Furthermore, an in-frame deletion mutant, in which an EcoRI-NdeI fragment internal to the ORF of interest was removed from pCI933, accounted for the loss of ENase activity (Fig. 2; Fig. 3, lane 7). As the ColEI origin of replication of pCI933 is unable to replicate in L. lactis, the shuttle vector $\mathrm{pCI} 372$, which contains the replication regions of plasmids pCI305 (isolated from $L$. lactis subsp. lactis UC317) and pBR322, was employed to reintroduce the fragment of interest into L. lactis. An XhoI-Sau3A fragment from pCI933 was subcloned into the compatible SalI/BamHI sites within the multiple cloning site of pCI372 (generating pCI934), and transformed into plasmid-free L. lactis subsp. cremoris MG1363. Analysis of cell-free extracts from transformants harbouring the 


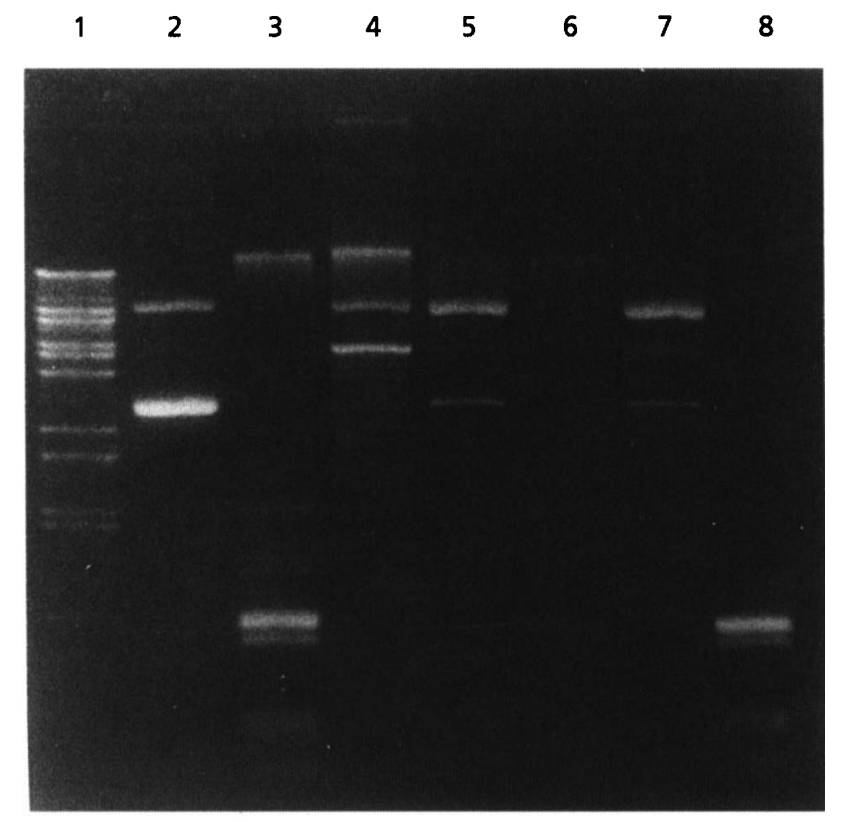

Fig. 3. Analysis of various $E$. coli and $L$. lactis cell-free extracts for SCrFI ENase activity. Lanes 3-7, pBR322 DNA treated with CFE from L. lactis subsp. cremoris UC503 (lane 3); L. lactis subsp. cremoris MG1363(pCl934) (lane 4); E. coli XL1-Blue MRF' (lane 5); $E$. coli XL1-Blue $\mathrm{MRF}^{\prime}(\mathrm{pCl}$ 1933) (lane 6); $E$. coli XL1-Blue MRF'(pCl942) (lane 7). Lane 1 , size markers ( $\lambda$ DNA digested with BstEII); lane 2, pBR322 DNA (uncut); lane 8, pBR322 DNA incubated with commercially purified ScrFI.

pCI934 construct exhibited ENase activity, although the activity was poor relative to $L$. lactis subsp. cremoris UC503 and E. coli XL1-Blue MRF' harbouring pCI933 (Fig. 3, lanes 4, 3 and 6, respectively). This analysis indicated that the ORF residing between the two $S c r F I$ MTase genes encoded the ScrFI ENase; consistent with the proposed nomenclature for genes associated with $\mathrm{R} / \mathrm{M}$ systems (Syzbalski et al., 1988), this gene was designated scrFIR.

When L. lactis subsp. cremoris MG1363 harbouring pCI934 was examined for in vivo restriction of the prolate-headed lactococcal phage $\phi \mathrm{c} 2$, no significant restriction was observed (Table 2 ). In contrast, substantial restriction was observed with $L$. lactis subsp. cremoris UC563, a derivative of the parent ScrFIproducing strain which has been cured of the cellsurface-exopolysaccharide-encoding plasmid pCI528, which masks biological R/M activity in UC503 (Table 2; Costello, 1988; Lucey et al., 1992; Davis et al., 1993). Evidence that the $S c r F I R / M$ system contributed to the $10^{5}$-fold reduction in EOP observed, rather than an alternative $\mathrm{R} / \mathrm{M}$ system encoded by UC563 being wholly responsible, was provided by purifying $\phi \mathrm{c} 2$ which had been passaged through MG1363(pCI934) (containing both $s c r F I A M$ and $s c r F I B M$ ) and reinfecting the ScrFIproficient host, UC563. Phage recovered from MG1363 (pCI934) were methylated by the ScrFI MTase(s) and
Table 2. Assessment of lactococcal strains for biological ScrFI R/M activity

$\phi \mathrm{c} 2 . \mathrm{MG} 1363, \phi \mathrm{c} 2 . \mathrm{UC5} 53$ and $\phi \mathrm{c} 2 . \mathrm{pCI} 934$ refer to $\phi \mathrm{c} 2$ recovered from single-plaque isolates following infection of $L$. lactis subsp. cremoris MG1363, UC563 and MG1363(pCI934), respectively. EOP data are expressed as the ability of $\phi \mathrm{c} 2$ to infect the strain of interest relative to the non-restricting host, L. lactis subsp. cremoris MG1363.

\begin{tabular}{|llc|}
\hline Phage & $\begin{array}{c}\text { L. lactis subsp. } \\
\text { cremoris host }\end{array}$ & $\begin{array}{c}\text { Efficiency of plaquing } \\
\text { (EOP) }\end{array}$ \\
\hline$\phi c 2 . M G 1363$ & MG1363 & $1 \cdot 0$ \\
$\phi c 2 . M G 1363$ & MG1363(pCI372) & $1 \cdot 1$ \\
$\phi c 2 . M G 1363$ & MG1363(pCI934) & $0 \cdot 8$ \\
$\phi c 2 . M G 1363$ & $\mathrm{UC563}$ & $1 \cdot 5 \times 10^{-5}$ \\
$\phi c 2 . U C 563$ & $\mathrm{UC563}$ & $0 \cdot 8$ \\
$\phi c 2 . \mathrm{pC} 934$ & $\mathrm{UC563}$ & $1 \cdot 2 \times 10^{-2}$ \\
\hline
\end{tabular}

displayed considerable resistance to $S c r F I$ digestion when used to infect UC563, as manifested by a $10^{3}$-fold increase in the EOP (Table 2). Therefore, while biochemical evidence indicated that the $S c r$ FI ENase was expressed in the recombinant plasmids, pCI933 and pCI934, classical in vivo plaque assays suggested that it was expressed too poorly to efficiently restrict phage. Nevertheless, in vivo expression of the ScrFI MTase(s) was observed.

The role of orf $X$, if any, in the $S c r F I R / M$ system is unclear. Removal of the $5^{\prime}$ end of orf $X$, including the putative promoter region and an inverted repeat structure, was accomplished by introducing a $3.8 \mathrm{~kb} \mathrm{HaeIII-}$ Sau3A fragment from pCI933 into the multiple cloning site of pCI372 (Fig. 2). However, even though E. coli transformants containing the correct insert were successfully obtained (construct designated pCI940; Fig. 2), these chimeras appeared to be toxic to the host as it grew poorly in broth and produced only pinpoint colonies on solid media (data not shown). Subsequent retransformation of pCI940 DNA into E. coli gave rise to a mixed pinpoint/regular colony phenotype, with the smaller colonies correlating with the presence of the correct insert, and larger ones with a $\mathrm{Cm}^{\mathrm{r}}$ deletion derivative. No further analysis was performed with these unstable constructs.

\section{Sequence analysis and organization of the ScrFI R/M system}

orf $X, s c r F I B M$ and $s c r F I R$ were found to be in-frame and to closely abut each other, with just 3 and 18 nucleotides between the respective ORFs, making it highly probable that all three are co-transcribed as a polycistronic message. Several sequences consistent with lactococcal promoters (van de Guchte et al., 1992) were evident upstream of orf $X$ (Fig. 1). Apart from an 
(a)

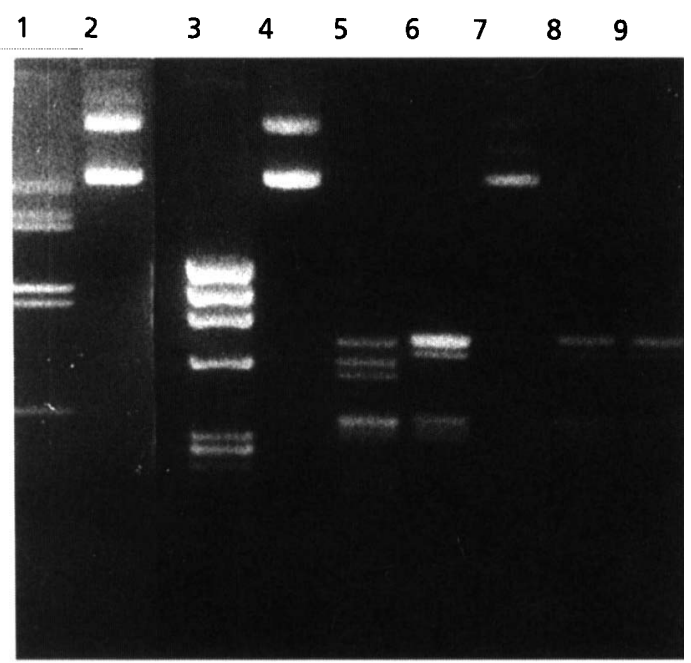

(b)

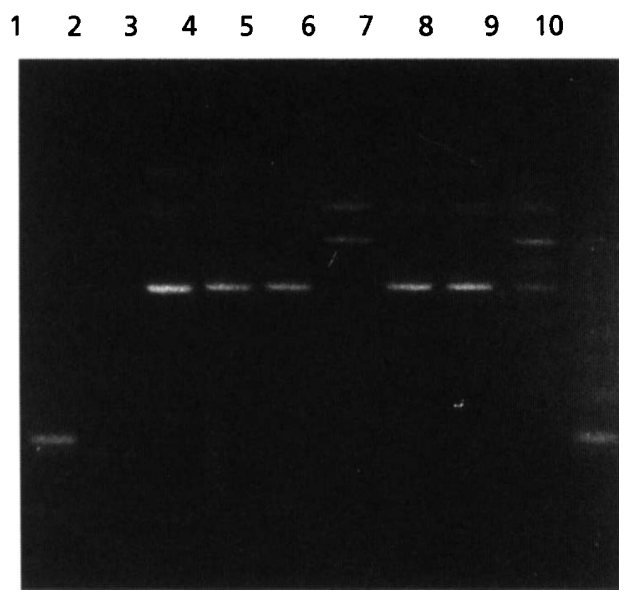

Fig. 4. (a) Demonstration that ScrFI is unable to cleave pBR322 DNA at $5^{\prime}$ CCWGG $3^{\prime}$ sites when isolated from a Dem-proficient $E$. coli host, due to the occurrence of $5 \mathrm{mC}$ at the $3^{\prime}$ cytosine in these sites. The cleavage pattern generated by ScrFI with DNA isolated from a Dcm-proficient host is similar to that of Ncil, which cleaves at $5^{\prime}$ CCSGG $3^{\prime}$ sites, a subset of the ScrFl recognition site. Lanes: 1 , pBR322 (Dcm $\left.{ }^{-}\right)$, EcoRII (5' CCWGG $\left.3^{\prime}\right)$; 2, pBR322 $\left(\mathrm{Dcm}^{-}\right)$, uncut; 3 , DNA size markers ( $\phi \times 174$ DNA digested with Haelll); 4, pBR322 (Dcm $\left.{ }^{-}\right)$, uncut; 5, pBR322 $\left(\mathrm{Dcm}^{-}\right)$, ScrFI $\left(5^{\prime}\right.$ CCNGG 3'); 6, pBR322 (Dcm $\left.{ }^{-}\right)$, Ncil (5' CCSGG $\left.3^{\prime}\right) ; 7$, pBR322 $\left(\mathrm{Dcm}^{+}\right)$, uncut; 8, pBR322 (Dcm $)$, ScrFI; 9, pBR322 $\left(\mathrm{Dcm}^{+}\right), \mathrm{Ncil}$. (b) Assessment of the effect of non-canonical modifications in impairing ScrFI digestion. pBR322 DNA was isolated from a Dcm-proficient $E$. coli host and therefore only $5^{\prime}$ CCSGG $3^{\prime}$ sites are amenable to digestion by SCrFI. Lanes 1-3, pBR322 DNA incubated with: ScrFl (5 U) (lane 1); Mspl (5 U) (lane 2); uncut (lane 3). Lanes 4-6, pBR322 DNA methylated in vitro with M.Sssl: uncut (lane 4); treated with Hpall (5 U) (lane 5); treated with ScrFI (1 U) (lane 6). Lanes 7-10, pBR322 DNA methylated in vitro with M.Mspl: uncut (lane 7); treated with Mspl (5 U) (lane 8); treated with ScrFI (1 U) (lane 9); treated with ScrFI (15 U) (lane 10).

inverted repeat region which could potentially form a stem-loop structure and which was located immediately after scrFIAM, no other significant secondary structure suggestive of a factor-independent transcriptional terminator was observed downstream of the other ORFs, indicating that all four genes may be transcribed as one message in an operon structure. However, the relatively larger distance of 164 nucleotides between $s c r F I R$ and scrFIAM, and the occurrence of putative promoter sequences in this intervening region, also support the possibility that $s c r F I A M$ may have its own independent promoter. In support of the latter proposal, a number of constructs (e.g. pCI931m) containing scrFIAM and its putative promoter region were capable of encoding an active MTase independent of the remainder of the ScrFI $\mathrm{R} / \mathrm{M}$ locus (Twomey, 1996).

\section{Comparison of Scrfl ENase with other proteins}

The deduced amino acid sequence encoded by $s c r F I R$ was examined for homology with protein sequences in the databases, SWISS-PROT (release 32), GenBank (release 92) and EMBL (release 45), using the BLAST suite of programs (Altschul et al., 1990). No significant homology was observed to any known proteins, including the ScrFI isoschizomer, SsoII, from Shigella sonnei, which also recognizes $5^{\prime}{ }^{\downarrow} \mathrm{CCNGG} 3^{\prime}$ but cleaves at a different location as indicated (Karyagina et al., 1993). Although the sequence motif $\operatorname{PDX}_{10-30}(\mathrm{D} / \mathrm{E}) \mathrm{XK}$ (where $\mathrm{X}$ is any amino acid) has been identified in a number of type II ENases, with the conserved residues forming the active site in EcoRI and EcoRV (Anderson, 1993), no such motif was identified in ScrFI.

\section{Assay for activity of SCrFI on 5mC-modified DNA}

The successful stable maintenance and expression of a type II ENase requires that recognition sites on the host genome are appropriately methylated by the cognate MTase(s) to prevent autodigestion. It has been proposed that $S c r F I$ is incapable of cleaving its recognition site, $5^{\prime}$ CCNGG $3^{\prime}$, when the second cytosine in each strand of the duplex is $5 \mathrm{mC}$, but cuts when the $5^{\prime}$ terminal Cresidue is similarily modified (McClelland et al., 1994). Therefore, modification of the second $\mathrm{C}$ is believed to be the canonical or true modification observed in lactococcal DNA encoding the $S c r F I R / M$ system (unpublished results). This was partially verified by the fact that DNA isolated from $E$. coli encoding the $5 \mathrm{mC}$ MTase M.Dcm, which modifies the internal cytosine in $5^{\prime}$ CCWGG $3^{\prime}$ sites (where $\mathrm{W}=\mathrm{A}$ or $\mathrm{T}$ ), remained refractory to cleavage by $S c r F I$ at these sites and effectively generated an altered ENase cleavage specificity, 5' CCSGG 3' (where $\mathrm{S}=\mathrm{C}$ or G; Nelson et al., 1984; Fig. 4a, lanes 5 and 8). The ability of the ScrFI ENase to cleave non-canonically modified sites in pBR322 was investigated. As this DNA was recovered from a Dcm-proficient strain (E. coli RR1) only $5^{\prime}$ CCSGG $3^{\prime}$ sites are susceptible to ScrFI digestion. Asymmetric bimethylation of these $5^{\prime}$ CCSGG $3^{\prime}$ sites in which the second cytosine of one strand and the central or outer cytosine of the other strand were modified was accomplished by in vitro methylation with M.SssI $\left(5^{\prime}\right.$ CG $\left.3^{\prime}\right)$ and M.MspI ( $5^{\prime}$ CCGG $\left.3^{\prime}\right)$, respectively (Figs $4 b$ 
(a)

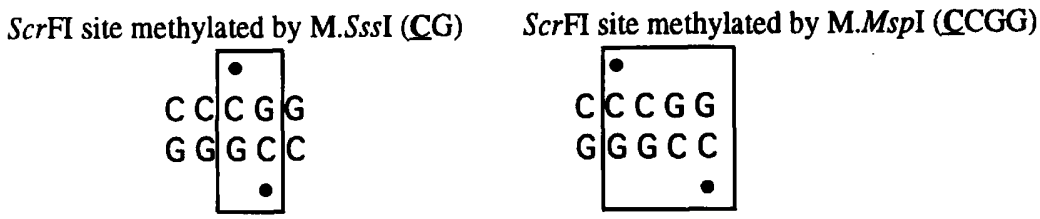

(b)

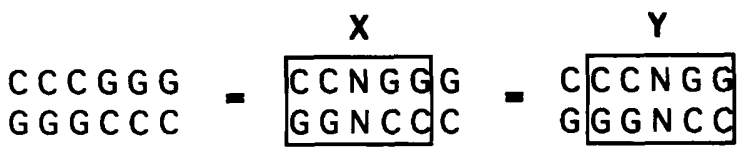

C C G G G
G G C C

and 5a). Incubation of $1 \mathrm{U} S c r F I$ ENase with either modified substrate for $1 \mathrm{~h}$ at $37^{\circ} \mathrm{C}$ resulted in partial digestion (Fig. 4b, lanes 6 and 9), with higher enzyme concentrations ( $15 \mathrm{U}$; Fig. $4 \mathrm{~b}$, lane 10 ) leading to substantial restriction, illustrating that while non-canonical modifications slow down the rate of digestion, there is nevertheless an appreciable degree of digestion. Therefore, this evidence suggests that lactococcal cells expressing the ScrFI ENase need to fully protect themselves from autodigestion by canonical modification of both strands of the $S c r F I$ recognition site.

\section{DISCUSSION}

ScrFI was the first type II ENase isolated from the industrially important lactococci and it remains the only one which is commercially available (Fitzgerald et al., 1982). Identification of the ENase gene in close association with the two previously described MTase genes, scrFIAM and scrFIBM (Davis et al., 1993; Twomey et al., 1993), was not unexpected, as close gene linkage has been observed with all type II R/M systems characterized to date (Wilson \& Murray, 1991). This close linkage presumably reflects the interdependent nature of the enzymes that constitute the system, which requires co-ordinated regulation of expression of the genes involved to permit protection of the host DNA, while still providing an effective barrier to foreign DNA.

The absence of pronounced homology between the deduced sequences of the two isoschizomers, ScrFI and SsoII, is not unusual as the primary sequences of type II
ENases are generally quite diverse and only isoschizomers which cleave at an identical position (i.e. homoschizomers) show substantial amino acid similarity (for reviews see Wilson \& Murray, 1991; Roberts \& Halford, 1993). In addition, the organization of the genes in these two $5^{\prime}$ CCNGG 3 '-specific systems differs as the respective ORFs are divergently transcribed in the SsoII system, but are co-directionally transcribed in ScrFI. Therefore, despite significant amino acid identity between M.SsoII and the ScrFI MTases $(70 \%$ and $27 \%$ identity with M.ScrFIA and M.ScrFIB, respectively), the ENases are quite different, suggesting that the cognate enzymes have independent lines of evolution or alternatively, the ENases have divergently evolved from a primitive precursor to such an extent so as to be unrecognizable by primary sequence comparisons. Furthermore, based on the ability to cleave synthetic substrates containing non-nucleotide inserts, Kubareva et al. (1992) have demonstrated that the ScrFI and SsoII ENases interact with their substrates in a fundamentally different manner.

Despite evidence for ENase activity in CFEs of hosts containing scrFIR, no apparent in vivo restriction of phage was observed. This result was unexpected, as the phage used in the assay contained several sites theoretically amenable to cleavage by $S c r F I$. Indeed, $\phi c 2$ has been used routinely in the laboratory to test lactococcal strains for classical $S c r F I ~ R / M$ activity. The reason for the absence of restriction is unclear; however, it is possible that the natural regulation between the respective ENase and MTase activities has been disrupted, 
causing expression of the ENase gene to be delayed, or the increased copy number of the cloned derivatives may have altered the natural synergy between the ENase and MTase activities, allowing the phage to become fully modified prior to restriction. Alternatively, the natural expression signals for efficient restriction activity may be absent in the cloned derivatives. It is also of interest to note that phage passaged through $L$. lactis subsp. cremoris MG1363 harbouring pCI934 are not fully resistant to restriction in $L$. lactis subsp. cremoris UC563, as an EOP of less than one $\left(1.2 \times 10^{-2}\right.$; Table 2$)$ was observed. This may be due to incomplete protection of $5^{\prime}$ CCNGG 3' sites against ScrFI digestion or may indicate the presence of a second $\mathrm{R} / \mathrm{M}$ system in $L$. lactis subsp. cremoris UC563. Attempts to enhance restriction activity by cloning scrFIR downstream of a strong promoter (P32 in pMG36e; van de Guchte \& Venema, 1989), and introducing these constructs into lactococcal hosts previously modified by the $S c r$ FI MTases, were unsuccessful.

The evidence presented here suggests that $S c r F I$ sites must be canonically modified on both strands to be fully resistant to $S c r F I$ digestion, i.e. the second cytosines in both strands of the duplex, $5^{\prime}$ CCNGG $3^{\prime}$ sites must be methylated at the 5-carbon position. The rationale for studying the ability of non-canonical modifications to impair ENase cleavage in the first instance relates to the degeneracy of the ScrFI ENase. Since the central nucleotide in the $S c r \mathrm{FI}$ recognition site $\left(5^{\prime} \mathrm{CCNGG} 3^{\prime}\right)$ is completely degenerate, in certain sequence contexts the ScrFI ENase may potentially cleave its target sequence, even if some non-canonical bases within this site have already been modified by one of the ScrFI MTases. An example of such a sequence is $5^{\prime}$ CCCGGG $3^{\prime}$ (i.e. a SmaI site) which is essentially two adjacent overlapping $S c r F I$ sites (Fig. 5b, X and Y). If one of the $S c r F I$ sites (X) is canonically modified on both strands by either of the ScrFI MTases, it should be refractory to cleavage. However, the adjacent site (Y) is non-canonically modified and is potentially susceptible to cleavage, requiring further modification to be fully protected. Therefore, some $\operatorname{Scr}$ FI sites, which would be predicted to occur rarely on the lactococcal genome, may need to have two adjacent cytosines methylated on the one strand to prevent the degenerate ENase from cleaving. Considering that many MTases are impaired by noncanonical modifications within their target sequence (Nelson \& McClelland, 1987), modification of two adjacent cytosines may require two fundamentally different MTases, which differ with respect to their ability to be sterically hindered by prior modifications in their recognition site. The $S c r F I R / M$ system is unique among characterized $\mathrm{R} / \mathrm{M}$ systems in that it is the only one to date known to have two $5 \mathrm{mC}$ MTases associated with an ENase which recognizes a symmetrical recognition sequence. The function of these two MTases remains to be established but the ability of $S c r F I$ to cleave non-canonically methylated sites suggests that the two $S c r F I$ MTases may have evolved to counteract the degeneracy of the ScrFI ENase.

\section{ACKNOWLEDGEMENTS}

This work was supported by grants from the European Community BRIDGE (contract BIOT-CT91-0263[SSMA]) and BIOTECH (contract BIO2-CT94-3055) programmes and by the Food Sub-Programmes of the Operational Programme for Industrial Development, which is administered by the Irish Department of Agriculture Food and Forestry and supported by national and European Union funds.

\section{REFERENCES}

Aggarwal, A. K. (1995). Structure and function of restriction endonucleases. Curr Opin Struct Biol 5, 11-19.

Altschul, S. F., Gish, W., Miller, W., Myers E. W. \& Lipman, D. J. (1990). Basic local alignment search tool. J Mol Biol 215, 403-410.

Anderson, D. G. \& McKay, L. L. (1983). Simple and rapid method for isolating large plasmid DNA from lactic streptococci. Appl Environ Microbiol 46, 549-552.

Anderson, J. E. (1993). Restriction endonucleases and modification methylases. Curr Opin Struct Biol 3, 24-30.

Bolivar, F., Rodriguez, R. L., Greene, P. S., Betlach, M. C., Heynecker, H. L., Boyer, H. W., Crosa, J. H. \& Falkow, J. S. (1977). Construction and characterisation of new cloning vehicles. II. A multipurpose cloning system. Gene 2, 95-113.

Costello, V. (1988). Characterization of bacteriophage-host interactions in Streptococcus cremoris UC503 and related streptococci. PhD thesis, National University of Ireland, Cork.

Coulondre, C., Miller, J. H., Farabaugh, P. J. \& Gilbert, W. (1978). Molecular basis of substitution hotspots in Escherichia coli. Nature 274, 775-780.

Davis, R. (1992). Development of in vitro gene transfer in Lactobacillus species and restriction-modification in Lactococcus : biochemical and genetic analysis of the ScrFI system. $\mathrm{PhD}$ thesis, National University of Ireland, Cork.

Davis, R., van der Lelie, D., Mercenier, A., Daly, C. \& Fitzgerald, G. F. (1993). $S c r F I$ restriction-modification system of Lactococcus lactis subsp cremoris UC503 : cloning and characterisation of two ScrFI methylase genes. Appl Environ Microbiol 59, 777-785.

Fitzgerald, G. F., Daly, C., Brown L. R. \& Gingeras, T. R. (1982). ScrFI: a new sequence-specific endonuclease from Streptococcus cremoris. Nucleic Acids Res 10, 8171-8179.

Garvey, P., van Sinderen, D., Twomey, D. P., Hill, C. \& Fitzgerald, G. F. (1995). Molecular genetics of bacteriophage and natural phage defence systems in the genus Lactococcus. Int Dairy J $\mathbf{5}$, 905-947.

Gasson, M. J. (1983). Plasmid complements of Streptococcus lactis NCDO 712 and other lactic streptococci after protoplast curing. J Bacteriol 154, 1-9.

van de Guchte, M. \& Venema, G. (1989). Construction of a lactococcal expression vector: expression of hen egg white lysozyme in Lactococcus lactis subsp. lactis. Appl Environ Microbiol 55, 224-228.

van de Guchte, M., Kok, J. \& Venema, G. (1992). Gene expression in Lactococcus lactis. FEMS Microbiol Rev 88, 73-92.

Hayes, F., Daly, C. \& Fitzgerald, G. F. (1990). Identification of the minimal replicon of Lactococcus lactis subsp. lactis UC317 plasmid pCI305. Appl Environ Microbiol 56, 202-209.

Hill, C. (1993). Bacteriophage and bacteriophage resistance in lactic acid bacteria. FEMS Microbiol Rev 12, 87-108.

Hill, C., Miller, L. A. \& Klaenhammer, T. R. (1991). In vivo genetic exchange of a functional domain from a type II A methylase 
between lactococcal plasmid pTR2030 and a virulent bacteriophage. J Bacteriol 173, 4363-4370.

Holo, H. \& Nes, F. (1989). High frequency transformation by electroporation of $L$. lactis ssp. cremoris strains grown in glycine in osmotically stable media. Appl Environ Microbiol 55, 31193123.

Karyagina, A., Lunin, V. G., Degtyarenko, K. N., Uvarov, V. Y. \& Nikolskaya, I. I. (1993). Analysis of the nucleotide sequence and derived amino acid sequence of the $S$ soII restriction endonuclease and methyltransferase. Gene 124, 13-19.

Klaenhammer, T. R. \& Fitzgerald, G. F. (1994). Bacteriophages and bacteriophage resistance. In Genetics and Biotechnology of Lactic Acid Bacteria, pp. 106-168. Edited by M. J. Gasson \& W. de Vos. London: Chapman \& Hall.

Klimasauskas, S., Timinskas, A., Menkevicius, S., Butkiene, D., Butkus, V. \& Janulaitis, A. (1989). Sequence motifs characteristic of DNA [cytosine-N4] methyltransferases: similarity to adenine and cytosine-C5 DNA methylases. Nucleic Acids Res 17, 98239832.

Kubareva, E. A., Petrauskene, O. V., Karyagina, A. S., Tashlitsky, V. N., Nikolskaya, I. I. \& Gromova, E. S. (1992). Cleavage of synthetic substrates containing non-nucleotide inserts by restriction endonucleases. Change in cleavage specificity of endonuclease SsoII. Nucleic Acids Res 20, 4533-4538.

Kumar, S., Cheng, X., Klimasauskas, S., Mi, S., Pósfai, J. R., Roberts, J. \& Wilson, G. G. (1994). The DNA (cytosine-5) methyltransferases. Nucleic Acids Res 22, 1-10.

Lucey, M., Daly, C. \& Fitzgerald, G. F. (1992). Cell surface characteristics of Lactococcus lactis harbouring pCI528, a $46 \mathrm{~kb}$ plasmid encoding inhibition of bacteriophage adsorption. J Gen Microbiol 138, 2137-2143.

McClelland, M., Nelson, M. \& Raschke, E. (1994). Effect of sitespecific modification on restriction endonucleases and DNA modification methyltransferases. Nucleic Acids Res 22, 36403659.

Moineau, S., Walker, S. A., Vedamuthu, E. R. \& Vandenbergh, P. A. (1995). Cloning and sequencing of LlaDCHI restriction/ modification genes from Lactococcus lactis and relatedness of this system to the Streptococcus pneumoniae DpnII system. Appl Environ Microbiol 61, 2193-2202.

Nelson, P. S. \& McClelland, M. (1987). The effect of site-specific modifications on restriction-modification enzymes. Nucleic Acids Res 15, 219-230.

Nelson, P. S., Christ, C. \& Schildkraut, I. (1984). Alteration of apparent restriction endonuclease recognition specificities by DNA methylases. Nucleic Acids Res 12, 5165-5173.

Noyer-Weidner, M. \& Trautner, T. A. (1993). Methylation of DNA in prokaryotes. In DNA Methylation: Molecular Biology and Biological Significance, pp. 39-108. Edited by J. P. Jost \& H. P. Saluz. Basel: Birkhäuser Verlag.
Nyengaard, N. R., Falkenberg-Klok, J. \& Josephsen, J. (1996). Cloning and analysis of the restriction-modification system LlaBI, a bacteriophage resistance system from Lactococcus lactis subsp. cremoris W56. Appl Environ Microbiol 62, 3494-3498.

O'Sullivan, D. J., Zagula, K. \& Klaenhammer, T. R. (1995). In vivo restriction by LlaI is encoded by three genes, arranged in an operon with IlaIM, on the conjugative Lactococcus plasmid pTR2030. J Bacteriol 177, 134-143.

Pósfai, J., Bhagwat, A. S., Pósfai, G. \& Roberts, R. J. (1989). Predictive motifs derived from cytosine methyltransferases. Nucleic Acids Res 17, 2421-2435.

Roberts, R. J. \& Halford, S. E. (1993). Type II restriction endonucleases. In Nucleases, 2nd edn, pp. 35-88. Edited by S. M. Linn, R. S. Lloyd \& R. J. Roberts. Cold Spring Harbor, NY: Cold Spring Harbor Laboratory.

Sambrook, J., Fritsch, E. F. \& Maniatis, T. (1989). Molecular Cloning: a Laboratory Manual, 2nd edn. Cold Spring Harbor, NY: Cold Spring Harbor Laboratory.

Sanger, F., Nicklen, S. \& Coulson, A. R. (1977). DNA sequencing with chain-terminating inhibitors. Proc Natl Acad Sci USA $\mathbf{7 4}$ 5463-5467.

Schleifer, K. H. \& Kilpper-Bălz, R. (1987). Molecular and chemotaxonomic approaches to the classification of streptococci, enterococci and lactococci : a review. Syst Appl Microbiol 10, 1-9.

Syzbalski, W., Blumenthal, R. M., Brooks, J. E., Hattman, S. \& Raleigh, E. A. (1988). Nomenclature for bacterial genes coding for class-II restriction endonucleases and modification methyltransferases. Gene 74, 279-280.

Terzaghi, B. E. \& Sandine, W. E. (1975). Improved medium for lactic streptococci and their bacteriophage. Appl Microbiol 29, 807-813.

Timiniskas, A., Butkus, V. \& Janulaitis, A. (1995). Sequence motifs characteristic of DNA [cytosine-N4] and DNA [adenine-N6] methyltransferases. Classification of all DNA methyltransferases. Gene 157, 3-11.

Twomey, D. P. (1996). Molecular characterization of the ScrFI restriction/modification system from Lactococcus lactis ssp. cremoris. PhD thesis, National University of Ireland, Cork.

Twomey, D. P., Davis, R., Daly, C. \& Fitzgerald, G. F. (1993). Sequence of the gene encoding a second $S c r F I \mathrm{~m}^{5} \mathrm{C}$ methyltransferase of Lactococcus lactis. Gene 136, 205-209.

Wilson, G. G. (1992). Amino acid sequence arrangements of DNA-methyltransferases. Methods Enzymol 216, 259-279.

Wilson, G. G. \& Murray, N. E. (1991). Restriction and modification systems. Annu Rev Genet 25, 585-627.

Received 4 December 1996; revised 3 March 1997; accepted 7 March 1997. 